Management of the Difficult Airway. Practice guidelines for management of the difficult airway: an updated report by the American Society of Anesthesiologists Task Force on Management of the Difficult Airway. Anesthesiology 2003; 98: 1269-77.

2 Mizutani AR, Ozaki G, Benumof JL, Scheller MS. Auscultation cannot distinguish esophageal from tracheal passage of tube. J Clin Monit 1991; 7: 232-6.

\section{Lumbar tattoos and lumbar puncture: the emperor's new clothes?}

To the Editor:

In western countries, lumbar siting of tattoos has become a trendy location for young women. In 2002, Douglas and Swenerton warned about a theoretical risk of introducing exogenous pigments in the epidural space, after puncturing a tattoo during epidural anesthesia, that would lead to epidermal tumours and/or chemical arachnoiditis. ${ }^{1}$ The clinical concerns are quite legitimate: 1) iatrogenic intraspinal epidermoid tumours have been reported after lumbar punctures; 2) epidermal tissue coring has been shown to occur in several studies; 3 ) the precise composition of tattoo inks remains unknown; and 4) some by-products may have toxic/mutagenic properties under certain circumstances. ${ }^{2}$ The consequences of introducing these pigments into the epidural space are unknown. Therefore, "guidelines" have been proposed: puncturing in a free spot within the tattoo; selecting another free vertebral interspace; nicking the skin before insertion of the needle or avoiding epidural anesthesia. ${ }^{3}$

While the debate on this issue continues ${ }^{4}$ the anesthesiologist who has to deal with the anxiety of the tattooed parturient is left with considerable uncertainty regarding the risks of performing epidural anesthesia. To date, however, no complication related to tattoo puncture during epidural anesthesia has been reported. We recognize that if there were a complication, clinical manifestations might not be apparent until several years later, as injected cells grow slowly. The carcinogenic potential of tattoo inks is still unclear. Despite the few reported cases of skin cancers associated with tattooes, this association is considered so far coincidental.

The risk of epidermoid tumours is related to tissue coring during puncture, not to tattooing. This complication was described well before tattooes regained popularity and lumbar tattoos became an issue. ${ }^{1}$ Every year, thousands of parturients undergo epidural anesthesia without any complications. It is uncertain how many of these patients are informed of a potential risk of "epidermal tumour by tissue coring." Interestingly, the lumbar tattoo seems to be a matter of concern only for epidural analgesia. No article identifies concerns related to lumbar puncture through a tattoo. Perhaps it is a simply a matter of time before neurologists or rheumatologists have to confront this issue too.

Lastly, histological aspects of tattooing provide crucial data. ${ }^{5}$ The pigments, deposited in the epidermis after tattooing are progressively lost, while the superficial epidermal layers peel away. After healing, the epidermis is completely devoid of pigments. Therefore, it is unlikely that "epidermal tissue coring" includes any pigment. In the dermis, most of the pigments are assimilated by macrophages, which migrate to the lymphatics. Retained ink particles are mostly intracellular, located in perivascular macrophages and fibroblasts. If they were entrapped by a needle, the pigments are more likely to be intracellular than free. Thus, the complications will be the result of cellular introduction rather than to the pigment itself. Finally, if the anesthesiologist wishes to avoid entrapping pigments efficiently, he/she will have to perform a skin incision prior to needle insertion.

In conclusion, we believe that the concern of providing epidural analgesia in patients with lumbar tattoos has been overstated. In the absence of documented complications, it may be an appropriate time for anesthesiologists to re-evaluate this relative contraindication to epidural analgesia.

Nicolas Kluger MD*

Jean-Christian Sleth MD $\dagger$

Bernard Guillot MD*

CHU Montpellier, ${ }^{*}$ Polyclinique Saint-Roch, $\dagger$

Montpellier, France

No funding received.

E-mail: nicolaskluger@yahoo.fr

Accepted for publication July 19, 2007.

\section{References}

1 Douglas MJ, Swenerton JE. Epidural anesthesia in three parturients with lumbar tattoos: a review of possible implications. Can J Anesth 2002; 49: 1057-60.

2 Engel E, Santarelli F, Vasold R, et al. Establishment of an extraction method for the recovery of tattoo pigments from human skin using HPLC diode array detector technology. Anal Chem 2006; 78: 6440-7.

3 Raynand L, Mercier FJ, Auroy $\Upsilon$, Benbamou D; SOS $A L R$. Epidural anaesthesia and lumbar tattoo: what to do? (French). Ann Fr Anesth Reanim 2006; 25: 71-3.

4 Muddle S. Tattoo or not to do? Int J Obstet Anesth 2006; 15: 259-60.

5 Sleth JC. Epidural anaesthesia and lumbar tattoo. Histology of tattoo: the missing link? (French). Ann Fr Anesth Reanim 2007; 26: 266-7. 